\title{
SOBRE LA ADMISIBILIDAD DE LA PRUEBA TESTIMONIAL MEDIANTE DECLARACIONES JURADAS ESCRITAS EN EL MARCO DEL ARBITRAJE DOMÉSTICO Y COMERCIAL INTERNACIONAL
}

\author{
ABOUT THE ADMISSION OF DEPOSITION OF WITNESSES BY \\ WRITTEN IN DOMESTIC ARBITRATION AND COMMERCIAL \\ INTERNATIONAL ARBITRATION
}

MIGUEL JOSÉ DIBARRART FERRADA*

\section{RESUMEN}

Una práctica muy utilizada, que cuenta con base normativa, consiste en la producción de la prueba testimonial por medio de una declaración jurada, escrita y firmada por su autor, lo cual se traduce en un gran beneficio y eficiencia en la destinación de recursos humanos y materiales tanto de las partes como del tribunal arbitral. El presente documento tiene por objeto analizar, por una parte, cómo regulan esta práctica los distintos sistemas jurídicos y reglamentos de centros especializados de arbitraje y si la práctica descrita es admisible o si, por el contrario, afecta los derechos de las partes en el proceso.

Palabras clave: arbitraje, autonomía de la voluntad, debido proceso, prueba testimonial, principio de contradicción, admisibilidad probatoria.

* Abogado, Licenciado en Derecho, Pontificia Universidad Católica de Chile. Magíster en Derecho Privado, Universidad de Concepción. Prof. Ayudante de Derecho Civil, Pontificia Universidad Católica de Chile, Santiago, Chile. Correo electrónico mjdibarr@uc.cl.

Artículo recibido el 11 de junio de 2019, y aprobado para su publicación el 9 de diciembre de 2019. 


\section{ABSTRACT}

A useful practice, which have normative recognition, is the deposition of witnesses by written, which it involves efficient use of human and economic resources for the parties and the arbitrator or panel. This document has for objectives analyze how the different legislations and rules of specialized centers of arbitration regulate this practice and if it is admissible or, by contrary, if it affects procedural rights protected by due process.

Keywords: arbitration, free will, natural justice, witnesses, contradictory principle, admissibility of evidence.

\section{INTRODUCCIÓN}

En las páginas siguientes, el lector encontrará una breve recopilación de antecedentes relativos a la práctica forense de rendir la prueba testimonial por escrito, mediante los denominados affidavit, ${ }^{1}$ los posibles reproches que se han formulado o pueden formularse en contra de la misma, las respuestas esbozadas a tales reproches $\mathrm{y}$, finalmente, las conclusiones de la presente investigación, la cual dice relación con la procedencia de dicha forma de rendir la prueba testimonial. Si bien esta práctica es, como se dijo, muy utilizada, en ocasiones se presentan dudas en cuanto a su procedencia, especialmente por parte de abogados que pretenden poner en entredicho la correcta tramitación del proceso arbitral, sembrando ciertas dudas sobre la validez de dicha tramitación, del laudo y la posterior ejecución del mismo.

Como es sabido, la ejecutabilidad de un laudo es probablemente el aspecto más importante que deberá asegurar el árbitro, a fin de que éste produzca los efectos que las partes han querido al momento de celebrar el compromiso. Muy vinculado con la ejecutabilidad se encuentra la garantía del debido proceso, y probablemente es lo que justifica que preguntas como la que motiva este artículo se aborden desde esa perspectiva. ${ }^{2}$ Nuestros

1 Entiéndase por tal a la "declaración jurada sobre puntos de hecho o de derecho". YRARRÁzAVAL Covarrubias, Arturo, Diccionario Jurídico-Económico, Ediciones Universidad Católica de Chile, Santiago, 2011, p. 51.

2 En este sentido, véase Kurkela, Matti; Turunen, Santtu, Due Process in International Commercial Arbitration, Oxford University Press, Nueva York, 2010, $2^{\text {a }}$ Ed., pp. 1-2. Me permito transcribir aquí, en su idioma original, un fragmento, haciendo la prevención de ser este tratado de un contenido 
Tribunales Superiores de Justicia no han conocido de recursos de nulidad fundados en la rendición de la prueba testimonial por escrito, mientras que han rechazado recursos de nulidad o reconocido laudos en que se invocaban otras irregularidades procesales para privarles de eficacia, ${ }^{3}$ varias de mayor magnitud, por lo que la pregunta planteada es más bien hipotética.

\title{
II. EL PRINCIPIODE AUTONOMÍA DE LA VOLUNTAD EN ELARBITRAJE
}

\author{
El presente estudio, enmarcado en la institución del arbitraje \\ doméstico y comercial internacional, ${ }^{4} \mathrm{y}$ por lo tanto se acota a la misma,
}

muchísimo más vasto de lo aquí expresado, proponiendo dichos autores -entre otras cosas- una cierta unificación doctrinaria del contenido del debido proceso en el arbitraje comercial internacional. El fragmento que por el momento nos importa para los acotados fines de este trabajo, es del siguiente tenor: "With this delegation of power comes a type of trade-off in the form of standards of quality applicable to arbitration. Making certain the award is enforceable is one of the most central duties of the arbitral tribunal. If the arbitral tribunal wants to issue an enforceable award, the process has to meet certain quality standards. These minimum quality standards are, of course, procedural. They can be called due process requirements just like the minimum procedural safeguards necessary for someone to be deprived of his property or other rights. As such, they can be considered aspects of such elements as procedural fairness, opportunity to be heard, and equal treatment as well as access to justice". En una nota al pie insertada en el fragmento recién citado, el autor cita a KAUFMANN-KoHLER, Gabrielle, "Globalization of Arbitral Procedure", Vanderbilt Journal of Transnational Law, 2003, Vol. 36, (Oct.), p. 1321, en los siguientes términos: "A comparative review of recent statutes and cases shows a consensus about two overriding principles, and yet a third appears to be emerging. Party autonomy in matters of procedure and due process are both well established across national arbitration regimes. The term 'due process' here refers to a number of notions with varying names under different national laws, including natural justice, procedural fairness, the right or opportunity to be heard, the so-called principle de la contradiction and equal treatment. More recently, procedural efficiency has been increasingly advocated by scholarly writers and taken into account in practice by arbitral tribunal and courts. However, it has not achieved the same recognition as the first two principles". En nuestra Ley $\mathrm{N}^{\circ} 19.971$ sobre arbitraje comercial internacional, se incluyen tanto en el artículo 36, sobre las causales de denegación al reconocimiento o ejecución del laudo, como en el artículo 34, sobre el recurso de nulidad en contra del mismo, varias causales en que puede enmarcarse una infracción al debido proceso. Particular importancia reviste la causal de ser contrario el laudo al orden público de Chile, o bien que el reconocimiento o ejecución implique dicha contravención.

3 Véase Ossa GuZmán, Felipe; Zamora Wilson, Rosana, El Arbitraje Internacional en la Jurisprudencia, Editorial Legal Publishing, Santiago, 2014, pp. 94 y ss. y 102 y ss.

${ }^{4}$ Para un análisis de la prueba en tribunales internacionales de derecho público, véase PAÚL DíAz, Álvaro, "Prueba Testifical y Pericial en la Práctica de la Corte Interamericana de Derechos Humanos", Ius et Praxis, 2019, Año 25, $\mathrm{N}^{\circ}$ 1, pp. 19-48. Si bien la situación recogida por dicho autor no es enteramente trasladable, coincidimos con el reproche formulado a la práctica de la Corte Interamericana de Derechos Humanos en cuando a valorar del mismo modo los affidávits que las demás declaraciones testimoniales, sin que haya existido previo acuerdo en ese sentido. Así, el presente trabajo parte del supuesto que las partes, soberanas de regular el procedimiento que se les aplicará en un arbitraje doméstico o comercial internacional, establezcan voluntariamente dicha posibilidad, y siempre 
toma como presupuesto el principio de autonomía de la voluntad o libertad de las partes ${ }^{5}$ para fijar las reglas de procedimiento según las cuales se sustanciará el proceso arbitral entre ellas, quienes pueden determinar, por sí o por remisión a un reglamento elaborado por instituciones especializadas, la ley ritual del proceso. ${ }^{6}$ Como expresa Fernández, "la común voluntad de las partes debe primar en todo lo relacionado con la designación de los árbitros y el procedimiento arbitral, sin más límites que los que imponga el respeto al debido proceso y a la igualdad de las partes". ${ }^{7}$ Este principio es ampliamente reconocido por las leyes y convenios internacionales sobre el arbitraje. ${ }^{8}$ Ahora bien, ante la ausencia de regulación dada por las partes, comúnmente se suele recurrir, con mayor o menor libertad, a las que fije el Juez Árbitro y, finalmente, a la ley del país de la sede arbitral. ${ }^{9}$ En un sentido similar, es delineado el principio por Frank-Bernd WeIGAND. ${ }^{10}$ REDFERN y HunTER, en efecto, sostienen que una de las mayores atracciones del arbitraje internacional es que es un método flexible de resolución de controversias, reconociéndoles al tribunal y a las partes la máxima libertad para diseñar un procedimiento adecuado para la disputa específica que les concierne. ${ }^{11}$

Este principio lo definen y caracterizan diversos autores nacionales, como Patricio Aylwin, ${ }^{12}$ Fernanda VÁsquez, ${ }^{13}$ y Alejandro Romero y José Ignacio DíAZ. ${ }^{14}$

reservando al tribunal arbitral la facultad de contrainterrogar a los testigos, de oficio o a petición de parte. Todo ello, según se analizará en las secciones siguientes.

${ }^{5}$ Cfr. Merino Merchán, José F.; Chillón Medina, José Ma , Tratado de Derecho Arbitral, Ed. Aranzadi,

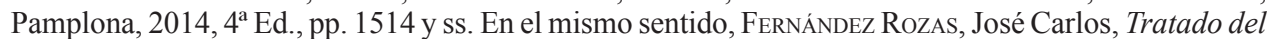
Arbitraje Comercial en América Latina, Iustel, Portal Derecho, Madrid, 2008, pp.709 y ss; y WeIGAND, Frank-Bernd, Practitioner's Handbook on International Commercial Arbitration, Oxford University Press, Nueva York, 2009, pp. 64 y ss.

${ }^{6}$ Cfr. Merino y Chillón, cit. (n. 5), p. 1515.

7 Fernández, cit. (n. 5), p. 712.

${ }^{8}$ Cfr. ídem.

9 Cfr. Merino y Chillón, cit. (n. 5), pp. 1514 y ss.

${ }^{10}$ Cfr. Weigand, cit. (n. 5), pp. 64 y ss.

${ }^{11}$ Cfr. Blackaby, Nigel; Partasides, Constantine; Redfern, Alan; Hunter, Martin, Redfern and Hunter on international arbitration, Oxford University Press, Nueva York, 2009, pp. 26-27.

${ }^{12}$ Aylwin Azócar, Patricio, El Juicio Arbitral, Legal Publishing, Santiago, 2014, 6 a Ed. actualizada, pp. 483 y 484. Expresa dicho autor lo siguiente: "El principio fundamental que la inspira [al artículo 636 del Código de Procedimiento Civil], es el de la autonomía de la voluntad de los compromitentes; (...)”.

${ }^{13}$ VÁsquez Palma, María Fernanda, Tratado de arbitraje en Chile. Arbitraje interno e internacional, Legal Publishing, Santiago, 2018, p. 702.

${ }^{14}$ Romero Seguel, Alejandro; Díaz Villalobos, José Ignacio, El arbitraje interno y comercial 
El ámbito de aplicación en que se enmarca este trabajo acota también el posible provecho del medio de prueba en análisis. En efecto, al ser el compromiso o compromisario un contrato, la mayoría de las disputas que se someten a un juez árbitro son relativas al incumplimiento de obligaciones de fuente contractual, área en la cual el valor de la prueba de testigos está sumamente restringida a nivel nacional ${ }^{15}$ y comparado, ${ }^{16}$ primando para estos efectos otros medios de prueba, como la instrumental. Debe recordarse que por estas restricciones se sostiene frecuentemente que en esta materia se mira a la prueba testimonial con cierto recelo o desconfianza. ${ }^{17}$

Previo a entrar en el análisis de los límites a la autonomía de la voluntad, parece conveniente plantear una breve reflexión sobre ciertas particularidades que se presentan en el arbitraje de frente al proceso civil, y que probablemente han contribuido a que la práctica objeto de estudio se encuentre presente en esta clase de procesos y no en otros. A diferencia de las normas de procedimiento civil, que están pensadas para una infinidad de situaciones para las cuales deben ser útiles y pertinentes, requiriendo la necesaria amplitud y generalidad para responder a todas ellas, las normas de procedimiento en el marco de un arbitraje son fijadas, en cada proceso, por los propios interesados. Esto permite que las partes pacten un verdadero "traje a medida", en resguardo de sus propios intereses. Así, si en un caso concreto estiman que es conveniente que cada parte solamente pueda presentar un informe de peritos, a fin de acotar el máximo de recursos que ambas pueden

internacional (parte general), Eds. Universidad Católica de Chile, Santiago, 2016, $2^{\text {a }}$ Ed. actualizada, p. 136. En particular, sobre la prueba testimonial, los señores Romero y Díaz sostienen lo siguiente: "Otro aspecto interesante de la prueba testimonial ha surgido en relación con la inhabilidad de los testigos que declaran en procedimiento seguido ante los arbitradores (...). La jurisprudencia ha establecido que su inhabilitación queda sujeta a la ponderación conforme a la sana crítica o equidad, quitándole el rigor a la tacha. Como consecuencia de lo anterior, algunos árbitros han desformalizado la rendición de la prueba testimonial en el arbitraje de equidad, estableciéndose en las reglas del procedimiento la libertad del árbitro para adoptar la forma de rendirla".

${ }^{15}$ En nuestro Derecho, destacan los artículos 1700, 1701, 1707, 1708, 1709, 1710 y 1711 del Código Civil. Especialmente relevante es la disposición siguiente: "No será admisible la prueba de testigos en cuanto adicione o altere de modo alguno lo que se exprese en el acto o contrato, ni sobre lo que se alegue haberse dicho antes, o al tiempo o después de su otorgamiento, aun cuando en algunas de estas adiciones o modificaciones se trate de una cosa cuyo valor no alcance a la referida suma".

${ }^{16}$ Sobre el particular, véase un estudio exhaustivo de los motivos y sus orígenes en Lessona, Carlo, Teoría de las pruebas en derecho civil, Editorial Jurídica Universitaria, México, 2001, Vol. II, pp. 285 y ss.

${ }^{17}$ Cfr. Bordalí Salamanca, Andrés; Cortez Matcovich, Gonzalo; Palomo Vélez, Diego, Proceso Civil. El juicio ordinario de mayor cuantía, procedimiento sumario y tutela cautelar, Legal Publishing, Santiago, 2014, $2^{\text {a }}$ Ed., p. 330. 
emplear, o bien si estiman que es conveniente fijar un cierto número máximo de testigos, o incluso regular la forma de producir una eventual prueba de confesión provocada, ${ }^{18}$ podrán hacerlo con el consiguiente beneficio que ellas mismas han tenido en cuenta al momento de fijar las bases de procedimiento. No olvidemos que es el propio legislador, en el caso del arbitraje y según se ha analizado, quien entrega este asunto a la voluntad de las partes. No sería imaginable semejante remisión en el caso del proceso civil, pues supondría un excesivo trabajo para los jueces conocer y fallar cada causa conforme a un procedimiento acordado especialmente por las partes para ella. Pero en el caso del arbitraje es distinto, pues el árbitro se ha constituido como tal precisamente para conocer excepcionalmente de esa controversia, para la cual las partes han creado un procedimiento que se ajusta lo más perfectamente a sus necesidades.

Dejando de lado la usual desconfianza que existe hacia la prueba testimonial, lo cual se ve reflejado, según hemos señalado, en una recepción bastante atenuada en materia contractual, materia que -recordemos- es precisamente aquella en la cual se suscitan la inmensa mayoría de las controversias cuya resolución es sometida a un árbitro, evitar el exceso de recursos que significa coordinar a las partes, sus abogados y al árbitro o miembros de un panel arbitral para concurrir, en simultáneo, a una audiencia que tiene por objeto interrogar a algún testigo cuya declaración versa sobre un aspecto importante, pero no decisorio, resulta un verdadero desperdicio en muchas ocasiones.

Por ejemplo, puede ser que en un contrato de construcción una de las partes reclame que la otra se negó a otorgar la recepción formal de las obras conforme a lo acordado en el contrato respectivo, pero que testigos que trabajaron en la obra afirmen que, al menos desde una cierta fecha, los edificios fueron ocupados y utilizados por la parte incumplidora. Así, resulta muy eficiente que las declaraciones de dichos trabajadores se aporten por escrito y que, si por alguna razón, la parte contra la cual se hacen valer o bien el árbitro estiman que hay motivos que hacen recomendable interrogar a alguno de dichos testigos en audiencia, se proceda en consecuencia. Lo cierto es que ya habrá un inmenso ahorro de recursos en la aportación de todas las demás declaraciones testimoniales, es decir, aquellas otorgadas por

\footnotetext{
${ }^{18}$ Por ejemplo, acordando que el pliego de posiciones enviado a la contraparte se responderá por escrito, o bien indicando que el propio árbitro pueda someter a las partes o a sus abogados a pliegos de preguntas.
} 
testigos sobre los cuales no hay indicios de que se logre un objetivo concreto tras su interrogatorio en audiencia o, dicho de otro modo, de cuyo contenido a nadie le interesa verdaderamente ahondar mediante un contrainterrogatorio. Así, los recursos se destinarán en forma eficiente, dirigiéndolos a interrogar sólo a aquellos testigos que, tras leer su declaración escrita, hacen sospechar a alguna de las partes o al juez que, a partir de su contrainterrogatorio, se obtendrá algo provechoso.

\section{LAS LIMITACIONES AL PRINCIPIO DE LA AUTONOMÍA DE LA VOLUNTAD}

Como ya se anunciaba en la cita contenida en el apartado anterior, la voluntad de las partes tiene, a lo menos, dos limitaciones: los derechos a la igualdad de las partes y al debido proceso (enunciados también como due process o natural justice). ${ }^{19}$ Dichas dos limitaciones, en realidad, pueden reducirse sólo a la primera de ellas, esto es, el debido proceso, en tanto estimamos que dicha garantía incluye la de igualdad de las partes, tal como se expresa más adelante.

Como dijera don Julio PhiLIPPI: ${ }^{20}$

¿Qué mejor resumen de las limitaciones del arbitrador que las señaladas por don Alfonso el Sabio en las Partidas?: 'Otrosí decimos, que si el mandamiento, o el juyzio de los auenidores fuesse contra nuestra Ley, o contra natura, o contra buenas costumbres; o fuesse tan desaguisado que non se pudiesse cumplir; o si fuese dado por engaño, por falsas prueuas, o por dineros; o sobre cosa que las partes non ouiessen metido en mano de los auenidores; por cualquier destas razones'.

Resulta, así, ineludible referirse -aunque brevemente- al debido proceso. Si bien el contenido del concepto "debido proceso" es algo difuso, nos limitaremos -a efectos de esta investigación- a acotarlo a nuestro medio

\footnotetext{
${ }^{19}$ Cfr. Weigand, cit. (n. 5), p. 94.

${ }^{20}$ Partida III, 4 ${ }^{\circ}$ 23, en Las siete partidas (Glosa del Lic. Gregorio López), Barcelona, Imp. de Antonio Bergner, 1844; cit. por Philippi Izquierdo, Julio, "Notas sobre el juicio seguido ante arbitradores", Revista de Estudios Jurídicos (PUC), 2013, Vol. 2, Nº 1-2, archivo de la Cámara de Arbitraje y Mediación de Santiago, disponible en línea: http://www.camsantiago.cl/articulos_online/20_Notas_ sobre_juicio_seguido.pdf. (fecha de visita: 19 de agosto de 2018).
} 


\section{jurídico y al proceso civil, ${ }^{21}$ en el cual -siguiendo a CORTEZ y PALOMO- ${ }^{22}$ se ha construido sobre los siguientes principios o derechos: (i) principio de igualdad de partes; (ii) principio de imparcialidad; (iii) derecho a la prueba; y (iv) principio o derecho al recurso. ${ }^{23}$ Según la jurisprudencia}

${ }^{21}$ Sobre el particular, hacemos notar que esta decisión puede ser controvertida, considerando que los valores resguardados por la garantía del debido proceso no son iguales en las diversas clases de procedimientos. Mientras no se elabore una doctrina internacional unificada sobre lo que significa o resguarda el debido proceso en el arbitraje, estimamos que el camino más seguro es asimilarlo al contenido de dicha garantía en el proceso civil. En lo que al arbitraje doméstico se refiere, estimo que ello está justificado al considerar las materias de arbitraje prohibido y el carácter de convención del compromiso, lo que acota las materias arbitrables a aquellas en que se ventila un interés privado. En este sentido, AyLwIN, cit. (n. 12), pp.124-125, expresa sobre el arbitraje prohibido lo siguiente: "Dos principios fundamentan esta restricción: Primero: Teniendo el arbitraje por base una convención y sólo pudiendo recaer ésta sobre objetos que estén en el comercio humano, no puede admitirse arbitraje sobre cosas incomerciables. Segundo: En gran número de litigios está comprometido más o menos directamente el interés social; se hace necesario, en consecuencia, sujetarlos a solemnidades especiales que sean una garantía de que no se resolverá ni hará nada lesivo para las superiores conveniencias de la sociedad o los legítimos derechos de terceros. La investidura privada de los jueces árbitros los obliga a respetar sólo los términos del compromiso, vale decir, la voluntad de los interesados, al margen de un eficaz control que vele por aquellos intereses; la facultad que tienen las partes de concederles poderes de arbitradores les permite fallar con prescindencia de los mandatos imperativos de la ley. Esto bien puede ocurrir, sin daño alguno, en los asuntos en que entran en juego únicamente los intereses privados de los litigantes, pero no cuando pueden verse afectados el orden público, las buenas costumbres o los derechos de terceros extraños al juicio. Por estas razones está negado a las partes el derecho de someter a compromiso los litigios que no sean de su interés puramente particular. Tal prohibición es consecuencia lógica de la naturaleza misma del juicio arbitral'. Por su parte, el arbitraje comercial internacional por definición implica una conclusión semejante. REDFERN y HUNTER, cit. (n. 11), p. 13, expresan sobre el particular lo siguiente: " $(f)$ The meaning of 'commercial'. (...) The first of the major treaties on international arbitration, the 1923 Geneva Protocol, started with the assumption that commercial matters would normally be capable of resolution (or settlement) by arbitration, whilst others might not be. The Protocol obliged each contracting State to recognize the validity of an arbitration agreement concerning disputes that might arise from a contract 'relating to commercial matters or to any other matter capable of settlement by arbitration'. The distinction that is made in the Protocol between 'commercial matters' and others carries with it the implication that 'commercial matters' will necessarily be capable of being settled (or resolved) by arbitration, under the law of the State concerned (because the State will permit such matters to be resolved by arbitration), whils it may (or may not) allow other matters to be resolved in this way".

${ }^{22}$ Cfr. Cortez Matcovich, Gonzalo; Palomo Vélez, Diego, Proceso Civil. Normas comunes a todo procedimiento e incidentes, Legal Publishing, Santiago, 2018, pp. 15-30.

${ }^{23}$ Existen otras sistematizaciones, pero hemos seguido la de los profesores CORTEZ y PALOMO, cit. (n. 22), por su claridad, actualidad y contexto en nuestro medio nacional. En España, lo recoge en términos más acotados Robles-Garzón (dir.), Conceptos Básicos de Derecho Procesal Civil, Tecnos, Madrid, 2012, 3 ${ }^{a}$ Ed., pp. 136-138. Dicha obra identifica un contenido de tres principios jurídicos naturales, que podríamos identificar con el contenido de la garantía al debido proceso: i) el principio de audiencia o a ser oído; ii) el principio de igualdad; y iii) el principio de dualidad de partes. En el marco en que se sitúa este trabajo, véase KuRKELA y TuRUnEn, cit. (n. 2), pp. 1-2. En esta última obra, relativa al debido proceso en el arbitraje comercial internacional, se identifican, a grandes rasgos, como aspectos del debido proceso, el derecho a ser oído y el trato igualitario, como asimismo el acceso a la justicia. En términos similares se expresa Born, Gary, International Commercial Arbitration, Transnational 
chilena citada por los autores antes referidos, el primer principio puede resumirse y caracterizarse como una "igualdad de armas", prohibiendo una desventaja de una parte frente a la otra e incluyendo una oportunidad de controvertir al oponente. El segundo principio dice relación con que el juez mantenga su carácter de tercero imparcial. ${ }^{24} \mathrm{El}$ tercer derecho dice relación con que exista un período de tiempo adecuado durante el cual se reciban las diligencias probatorias, que cada parte tenga el derecho de proponer los medios de prueba que estime convenientes para acreditar sus pretensiones y, finalmente, que el medio de prueba sea admitido y correctamente valorado. ${ }^{25}$ Incluiremos a propósito de este derecho el principio de bilateralidad de la audiencia, en cuanto exige que en todo procedimiento las partes tengan derecho a controlar la producción de la prueba aportada por su contraparte. ${ }^{26}$ El cuarto de los principios o derechos que forman parte del contenido de la garantía al debido proceso (el denominado derecho al recurso) es el que más controversia presenta, al menos en nuestro sistema procesal, al analizar las diversas reformas legales, efectuadas o en vías de tramitación. ${ }^{27}$ Lo relevante es que no cabe duda de que se trata de un derecho que escapa al problema que es objeto de la presente investigación, pues dice relación, más bien, con la posibilidad de impugnar la sentencia definitiva, sea mediante la doble instancia o con la mera consagración de un recurso extraordinario de nulidad, cuestión que se discute en nuestro país. ${ }^{28}$

Descartado que sea, entonces, el principio o derecho al recurso (por inconexo con la materia en estudio), cabrá en la sección V. referirnos a los restantes tres principios o derechos que conforman el contenido de la garantía al debido proceso en relación con la posibilidad de rendir la testimonial mediante declaraciones escritas.

Previo a ello, y sin emitir todavía una opinión sobre el respeto o vulneración a dicha garantía por parte de la práctica forense en estudio, se

Publishers, Nueva York, 2001, $2^{\mathrm{a}}$ Ed., pp. 832-834. No obstante las notas antes esbozadas, evidentemente un tratamiento más extenso o acabado del debido proceso claramente excede los límites de este trabajo. Pero fijados sus contornos, ello servirá para fijar los límites, según se ha señalado, del principio de autonomía de la voluntad para fijar las normas de procedimiento.

${ }^{24}$ Cfr. Ídem.

${ }^{25}$ Cfr. Ídem.

${ }^{26}$ Cfr. Romero Seguel, Alejandro. Curso de Derecho Procesal Civil. Tomo III. Los Presupuestos

Procesales Relativos al Procedimiento, Legal Publishing, Santiago, 2015, p. 26.

${ }^{27}$ Cfr. Ídem.

${ }^{28}$ Cfr. Ídem. 
expone una recopilación y análisis del tratamiento que dan las diversas leyes procesales y de arbitraje, como asimismo reglamentos de distintos centros de arbitraje, a la forma (escrita u oral) de rendir la prueba de testigos.

\section{LA DECLARACIÓN DE TESTIGOS POR ESCRITO EN LA LEGISLACIÓN}

\subsection{Generalidades}

La presente sección tiene por objeto analizar el tratamiento normativo que se da en Chile - como punto de partida- y en otros ordenamientos jurídicos, a la posibilidad de rendir la prueba de testigos mediante declaraciones juradas escritas. Si bien el marco de este trabajo dice relación con el arbitraje, y reconociendo que existen profundas diferencias entre los conflictos sometidos a arbitraje doméstico y comercial internacional, por una parte, y muchos de aquellos sometidos a los jueces ordinarios, por la otra, resulta necesario analizar -como punto de partida- cómo es tratada generalmente la producción escrita de la prueba testimonial en las diversas normas procesales civiles. Luego, se analiza también el tratamiento que se le da a este tema en algunas leyes y reglamentos específicos de arbitraje, que está vinculado más estrechamente con el objeto de este estudio.

\subsection{Situación en Chile}

En lo que al procedimiento civil ordinario respecta, nuestro sistema dispone una serie de formalidades y la práctica de la diligencia en audiencia oral, según puede leerse claramente, entre otros, en los artículos 359, 361, 365 a 369, y 380 del Código de Procedimiento Civil. ${ }^{29}$ Sólo se admite como excepción al procedimiento oral de examen de los testigos regulado

\footnotetext{
${ }^{29}$ En efecto, dispone el artículo 359 del Código de Procedimiento Civil que el testigo está obligado a concurrir a la audiencia correspondiente; el artículo 361, por su parte, que ciertas personas pueden hacerlo en audiencia en lugar y fecha que propongan; el artículo 365, a su turno, que el testigo será interrogado personalmente por el juez; el artículo 366 consagra el derecho de las partes a dirigir preguntas al testigo; el artículo 367 prohíbe a los testigos llevar escrita su declaración; los artículos 368 y 369 que la declaración constituye un solo acto que no puede interrumpirse y que el juez señalará una o más audiencias para el examen de los testigos, procurando que todos los de una parte sean examinados en la misma audiencia; y el artículo 380, finalmente, dispone que el testigo legalmente citado que no concurriera al día y hora de la citación, puede incluso ser compelido a presentarse por la fuerza.
} 
en el Código de Procedimiento Civil, las declaraciones de los chilenos o extranjeros que gocen en el país de inmunidad diplomática, en conformidad a los tratados vigentes sobre la materia, quienes declararán "por informe", si consintieran en ello (artículo 362 del Código de Procedimiento Civil).

En lo que a procedimiento arbitral se refiere, nuestra legislación orgánica y de procedimiento civil -excluyendo de este análisis a los árbitros de derecho, quienes, según los artículos 223 del Código Orgánico de Tribunales y 628 del Código de Procedimiento Civil, se someten, tanto en la tramitación como en el pronunciamiento de la sentencia definitiva, a las reglas que la ley establece para los jueces ordinarios-, dispone el artículo 636 del Código de Procedimiento Civil lo siguiente:

"El arbitrador no está obligado a guardar en sus procedimientos y en su fallo otras reglas que las que las partes hayan expresado en el acto constitutivo del compromiso".

En el mismo sentido, el artículo $19^{\circ}$ de la Ley $\mathrm{N}^{\circ} 19.971$ sobre arbitraje comercial internacional, establece lo que sigue:

“1) Con sujeción a las disposiciones de esta ley, las partes tendrán libertad para convenir el procedimiento a que se haya de ajustar el tribunal arbitral en sus actuaciones.

2) A falta de acuerdo, el tribunal arbitral podrá, con sujeción a lo dispuesto en esta ley, dirigir el arbitraje del modo que considere apropiado. Esta facultad conferida al tribunal arbitral incluye la de determinar la admisibilidad, la pertinencia y el valor de las pruebas".

Entenderemos que, si bien las normas sobre arbitraje en comento no permiten explícitamente la forma escrita para las declaraciones testimoniales, dejan en libertad de las partes -y en el caso de la ley de arbitraje comercial internacional, subsidiariamente al juez- para acordar un procedimiento de esta clase. A este principio, recogido en las normas antes citadas, que hemos llamado de autonomía o libertad de la voluntad, debe reconocérsele el límite que se ha visto en la sección III.

\subsection{Normas de procedimiento civil extranjeras}

El común de los códigos que regulan la forma de sustanciación de los juicios ordinarios en tribunales ordinarios o especiales, regula la prueba testimonial mediante audiencias desarrolladas en la presencia del juez y de 
los apoderados de las partes, salvo contadas excepciones en las cuales se permite declarar por escrito. Tales excepciones dicen relación ya sea con la imposibilidad de comparecer a las audiencias testimoniales como también con privilegios diplomáticos u otorgados a otra clase de personas en razón de su cargo o naturaleza. ${ }^{30}$ En tal sentido se encuentran nuestro Código de Procedimiento Civil, según se ha analizado, la Ley de Enjuiciamiento Civil Española, ${ }^{31}$ el Código de Procesal Civil y Comercial de la Nación Argentina $^{32}$ y el Código General del Proceso de Uruguay. ${ }^{33}$ El Código Procesal Civil Modelo para Iberoamérica también opta por la solución descrita anteriormente. ${ }^{34}$

El Código de Procedimiento Civil francés, ${ }^{35}$ por otra parte, recoge la posibilidad amplia de rendir la prueba testimonial mediante declaraciones escritas. Así, dispone en su artículo 199 del Capítulo IV del Libro I, que "En los casos en que resulte admisible la prueba testifical, el tribunal podrá recibir de terceros las declaraciones tendentes a esclarecer los hechos controvertidos de que aquéllos tuvieran conocimiento. Estas declaraciones podrán recibirse por escrito o bien a través de la práctica de un interrogatorio al testigo". ${ }^{36}$ En los artículos siguientes, bajo la sección primera, regula la forma de los certificados o attestations, estableciendo que éstos pueden

\footnotetext{
${ }^{30}$ Un ejemplo en el Derecho Comparado de personas imposibilitadas para declarar por su naturaleza lo constituyen las personas jurídicas, aunque dicha hipótesis encuadra también con la imposibilidad para declarar en forma oral.

${ }^{31}$ Cfr. artículos 364 y 381 de la Ley No 1-2000, Ley de Enjuiciamiento Civil española (2000), documento disponible en línea: https://www.boe.es/buscar/doc.php?id=BOE-A-2000-323 (visitada el 19 de agosto de 2018).

${ }^{32}$ Cfr. artículos 431, 442 y 455 de la Ley No 17.454 de 1981, Código Procesal de la Nación Argentina (1981), documento disponible en línea: http://www.legislaw.com.ar/legis/cpcc\%20completo/ cpcclibrosegundo.htm (visitada el 19 de agosto de 2018).

${ }^{33}$ Cfr. artículos 161 y 163 de la Ley N ${ }^{\circ} 15.982$ de 1988, Código General del Proceso Uruguayo (1988), documento disponible en línea: https://www.iberred.org/sites/default/files/cdigo-procesal-civiluruguay. pdf (visitada el 19 de agosto de 2018).

${ }^{34}$ Cfr. "Base ${ }^{\circ} 15 "$ del Tema II de las Bases para Preparación del Código Procesal Civil Modelo para Iberoamérica (1988), documento en pdf, disponible en línea: http://www.iibdp.org/images/ codigos_modelo/IIDP_Codigo_Procesal_Civil_Modelo_Iberoamerica.pdf(visitado el 19 de agosto de 2018); y los artículos 151 y 153 del Código Procesal Civil Modelo para Iberoamérica (1988), documento en pdf, disponible en línea: http://www.iibdp.org/images/codigos_modelo/IIDP_Codigo_ Procesal_Civil_Modelo_Iberoamerica.pdf (visitado el 19 de agosto de 2018).

${ }^{35}$ Reformado por Decreto N 460 de 2005.

${ }^{36}$ Las traducciones del francés original fueron hechas con el concurso del Dr. D. Fernando Gascón Inchausti, Profesor Titular de la Universidad Complutense de Madrid. V. Código Procesal Civil francés (1976), archivo disponible en línea: https://www.legifrance.gouv.fr/content/location/1758 (visitada el 19 de agosto de 2018).
} 
ser producidos por iniciativa de parte o del juez, que deben ser suscritos por personas que sean aptas para ser testigos y que el juez siempre puede proceder a examinar en audiencia al autor de un certificado. En el artículo 202 del mismo cuerpo legal, se regula en forma más detallada la forma de los certificados, pudiendo destacarse que, además de la individualización de su autor, se exige que se señalen relaciones de parentesco, afinidad o subordinación con las partes, relaciones de colaboración con ellas o la existencia de intereses comunes. Finaliza dicha disposición, indicando que "El informe habrá de ser escrito, fechado y firmado de propia mano por su autor. Habrá de acompañarle, sea en original o en fotocopia, un documento oficial que acredite su identidad y en el que aparezca su firma". ${ }^{37}$

Luego, en la sección segunda del Capítulo IV del Libro I del Código de Procedimiento Civil francés, se regulan los interrogatorios en forma similar a nuestro código.

El Código Procesal Civil alemán, o $Z P O^{38}$ también admite las declaraciones de testigos por escrito, cuando en virtud de su contenido y de la persona del testigo, ello aparezca como suficiente, debiendo, de todas formas, advertirse al testigo de que puede ser citado para declarar. En este caso, a diferencia del anteriormente analizado, se da al menos un criterio al juez para que pueda prescindir del interrogatorio oral.

\subsection{Normas de arbitraje extranjeras}

Por su parte, las normas que son más pertinentes a este estudio, a saber, las de procedimiento en sede arbitral, admiten muy mayoritariamente la facultad de las partes para acordar normas de procedimiento en que las testimoniales se rindan por declaraciones escritas, como asimismo -en muchos casos- la facultad del árbitro para requerir las testimoniales por escrito.

Disponen la oralidad como regla general, pero admiten expresamente la facultad de las partes de optar por la forma escrita a efectos de rendir

\footnotetext{
${ }^{37}$ Ibídem.

${ }^{38}$ Cfr. Parágrafo 377.3 del Código Procesal Civil alemán - ZPO (1867) reformada el 2005, Gaceta de Leyes Federales I, p. 3202, versión traducida al inglés disponible en línea: http://www.gesetze-iminternet.de/englisch_zpo/index.html (visitada el 19 de agosto de 2018).
} 
la prueba testimonial, países como China $^{39}$ e Italia. ${ }^{40}$ No disponen regla especial sobre la materia, dejando a las partes o al Árbitro la decisión, países como Austria, ${ }^{41}$ Hong Kong, ${ }^{42}$ Reino Unido, ${ }^{43}$ Francia, ${ }^{44}$ Alemania, ${ }^{45}$ Países Bajos $^{46}$ y Suiza ${ }^{47}$ En este último grupo de países, no obstante lo señalado, la testimonial mediante declaraciones escritas es una práctica habitual. ${ }^{48}$ No he encontrado legislaciones sobre arbitraje que expresamente prohíban esta forma de rendir la prueba testimonial.

En cuanto a los reglamentos de los centros de arbitraje, destacan el de la CNUDMI, ${ }^{49}$ el cual, en el número 5. de su artículo 25 dispone que "Los testigos podrán también presentar sus deposiciones por escrito y firmadas", ${ }^{50}$ y el reglamento del CIADI, ${ }^{51}$ que en su artículo 36 establece lo que sigue: "No obstante lo dispuesto en la Regla 34, el Tribunal podrá: a) Admitir la prueba proporcionada por un testigo o experto en una deposición

\footnotetext{
${ }^{39}$ Cfr. Weigand, cit. (n. 5), p. 287. V. artículo 39 de la Arbitration Law of the People's Republic of China (1994), archivo disponible en línea: http://www.npc.gov.cn/englishnpc/Law/2007-12/12/content_1383756. htm (visitado el 19 de agosto de 2018).

${ }^{40}$ Cfr. Weigand, cit. (n. 5), p. 574. V. artículos introducidos en materia de arbitraje por el Decreto Legislativo $\mathrm{N}^{\circ} 40$, de 2006, modifica el Código de Procedimiento Civil italiano, disponible en línea: http://www.camera.it/parlam/leggi/deleghe/06040dl.htm (visitada el 19 de agosto de 2018). En particular, artículo 816 - ter.

${ }^{41}$ Cfr. Weigand, cit. (n. 5), p. 141. V. artículos 594 y 598 de la Ley No 113 de 1895, Austrian Arbitration Act, Sección 577-618 del Código de Procedimiento Civil austríaco, documento en pdf., disponible en línea: http://www.viac.eu/images/ZPO_Schiedsrecht_2014_en_im_VIAC_Layout.pdf(visitado el 19 de agosto de 2018).

${ }^{42}$ Cfr. artículos 22.6 y 22.7, Administered Arbitration Rules (2013), Reglamento del Centro de Arbitraje Internacional de Hong Kong, documento en .pdf, disponible en línea: http://www.hkiac.org/sites/ default/files/ck_filebrowser/PDF/arbitration/2013_hkiac_rules\%28en_es\%29.pdf (visitada el 19 de agosto de 2018).

${ }^{43}$ Cfr. Weigand, cit. (n. 5), p. 378. V. artículo 34 de la U.K. Arbitration Act, de 1996, documento disponible en línea: http://www.legislation.gov.uk/ukpga/1996/23/section/34 (visitada el 19 de agosto de 2018).

${ }^{44}$ Cfr. Weigand, cit. (n. 5), pp. 445 y 446. V. artículos 1460 y 1461 del Código Procesal Civil francés, al que se ha aludido precedentemente (n. 36).

${ }^{45}$ Cfr. Weigand, cit. (n. 5), pp. 504 y 505. Ver parágrafo 1047 del ZPO, al que se ha aludido precedentemente.

${ }^{46}$ Cfr. Weigand, cit. (n. 5), p. 655.

${ }^{47}$ Cfr. Weigand, cit. (n. 5), p. 842.

${ }^{48}$ Cfr. Weigand, cit. (n. 5), pp. 141, 378, 445-446, 504-505, 655 y 842. V. notas al pie no 18 a 24.

${ }^{49}$ Comisión de las Naciones Unidas para el Derecho Mercantil Internacional.

${ }^{50}$ Merino y Chillón, cit. (n. 5), p. 1165.

${ }^{51}$ Centro Internacional de Arreglo de Diferencias Relativas a Inversiones.
} 
escrita". ${ }^{52}$ Reglas semejantes están contenidas en los reglamentos de la Asociación Americana de Arbitraje $^{53}$ y de la Comisión Interamericana de Arbitraje Comercial, ${ }^{54}$ de la Corte Española de Arbitraje, ${ }^{55}$ de la London Court of International Arbitration ${ }^{56} \mathrm{y}$ de la International Bar Association. ${ }^{57}$ Nótese que el año 2010 se revisó el reglamento de la CNUDMI, pero las modificaciones introducidas no alteraron la esencia de la norma en cuestión. Así, su actual artículo 27.2. establece lo siguiente: "A menos que el tribunal arbitral disponga otra cosa, las declaraciones de los testigos, incluidos los peritos, podrán presentarse por escrito, en cuyo caso deberán ir firmadas por ellos". 58

De lo anterior se extrae que todos de los centros de arbitraje analizados, y que son los de mayor prestigio mundial, reconocen la posibilidad de las partes de pactar, para rendir la prueba de testigos, la forma escrita, mediante declaraciones firmadas. ${ }^{59}$ Las autorizadas voces de Alan REDFERn y Martin HunTER se han expresado en un sentido similar, ${ }^{60}$ señalando que las reglas

\footnotetext{
${ }^{52}$ Merino y Chillón, cit. (n. 5), p. 1185.

${ }^{53}$ Ídem., p. 1216. Se trascribe lo pertinente "32. Prueba por declaración jurada y registro de documentos. El Arbitro admitirá y considerará la prueba de testigos bajo la forma de declaración jurada, pero dará a ella sólo aquel valor que el Arbitro considere que ella merece después de tomar en cuenta cualesquiera objeciones hechas a su admisión".

${ }^{54}$ Ídem., p. 1226. Se trascribe lo pertinente “Art. 25. (...) 5. Los testigos podrán también presentar sus deposiciones por escrito y firmadas".

${ }^{55}$ Cfr. artículo 25.2, Reglamento de la Corte Española de Arbitraje (2011), archivo disponible en línea: http://corteespanolaarbitraje.es/wp-content/uploads/2014/05/reglamento-corte-espanola-dearbitraje-en-vigor-desde-el-15-03-2011.pdf (visitado el 19 de agosto de 2018). El artículo en comento es del siguiente tenor: "Los árbitros podrán disponer que los testigos presten declaración por escrito, sin perjuicio de que pueda disponerse además un interrogatorio ante los árbitros y en presencia de las partes, en forma oral o por algún medio de comunicación que haga innecesaria su presencia. La declaración oral del testigo habrá de llevarse a cabo siempre que lo requiera una de las partes y así lo acuerden los árbitros".

${ }^{56} \mathrm{Cfr}$. artículo 20.2. London Court of International Arbitration (2014), documento disponible en línea: http://www.lcia.org/Dispute_Resolution_Services/lcia-arbitration-rules-2014.aspx\#Article\%2020 (visitada el 19 de agosto de 2018).

${ }^{57}$ Cfr. artículos 4 y 8.4., Reglamento sobre Práctica de Prueba en el Arbitraje Internacional de la International Bar Association (2010), IBA, Londres, 2010, texto no oficial en español, disponible en línea: https://www.ibanet.org/Document/Default.aspx?DocumentUid=3599492E-8BC6-4E3D-A205B86B69A42593 (visitada el 19 de agosto de 2018).

${ }_{58}$ artículo 27.2. Reglamento de Arbitraje de la CNUDMI (1966), revisión de 2010, ONU, Nueva York, 2011, texto en español, archivo .pdf, disponible en línea: https:/www.uncitral.org/pdf/spanish/texts/ arbitration/arb-rules-revised/arb-rules-revised-s.pdf, visitado el 19 de agosto de 2018.

${ }^{59}$ Véase Kurkela y Turunen, cit. (n. 2), pp. 162 y ss.

${ }^{60}$ Cfr. Blackaby, Partasides, Redfern y Hunter, cit. (n. 11), pp. 401 y ss.
} 
relativas a la admisibilidad de las declaraciones testimoniales escritas son, en principio, las mismas que se aplican a las declaraciones testimoniales prestadas en audiencia ante el Tribunal Arbitral. ${ }^{61}$

V. A NIVEL DOGMÁTICO: ¿ES ADMISIBLE LA PRÁCTICA RECOGIDA POR LAS LEYES Y REGLAMENTOS DE ARBITRAJE ANTES ANALIZADOS?

\subsection{Enunciado}

Habiendo sido someramente expuesta una parte de la legislación y práctica existentes en Chile y en el extranjero, a partir de las cuales hemos podido concluir que la práctica de rendir la prueba testimonial mediante declaraciones escritas -en una primera etapa y salvando siempre el derecho a examinar a los testigos en audiencia, por motivo fundado- es aceptada en varios ordenamientos jurídicos, corresponde analizar si dicha decisión es admisible en Derecho, al menos desde la perspectiva de la garantía del debido proceso, que constituye, según se señaló en la sección III, el verdadero límite al principio de autonomía de la voluntad en materia de arbitraje.

\subsection{Los posibles reproches a la declaración de testigos por escrito}

Entre los reproches formulados por la doctrina procesalista a la rendición de la testimonial mediante declaraciones escritas, podemos mencionar los siguientes: i) vulneración de la base o principio de contradictoriedad en el diligenciamiento de la prueba; ${ }^{62}$ ii) facilidades para mentir; ${ }^{63}$ iii) contactos entre la parte o su abogado y el testigo pondrían en entredicho su credibilidad ${ }^{64}$ ("preparación del testigo"); y iv) nula posibilidad de percibir por los sentidos las reacciones del testigo, las cuales incidirían en

\footnotetext{
${ }^{61}$ Cfr. ídem, pp. 404-405.

${ }^{62}$ Couture, Eduardo, Fundamentos del Derecho Procesal Civil, Editorial B. de F., Montevideo, 2002,

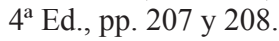

${ }^{63}$ Bentham, Jeremy, Tratado de las pruebas judiciales, Editorial Jurídica Universitaria, México, 2001, pp. 94-95. A la inversa, sería conveniente al impedir la intimidación de un testigo veraz, según expresa el mismo autor.

${ }^{64}$ Fernández, cit. (n. 5), p. 773.
} 
su credibilidad ${ }^{65}$ (por ejemplo, se nota que está mintiendo, se puso nervioso, reaccionó de una determinada manera que genera suspicacia, etc.).

Respecto del principio de contradictoriedad en el diligenciamiento de la prueba, estimamos que dicho principio se salvaguarda en muchas ocasiones con la oportunidad de la parte contra quien se hace valer la prueba para formular objeciones u observaciones -como ocurre en la prueba instrumental-, o bien, más propiamente en este caso, mediante la oportunidad para solicitar fundadamente la comparecencia del testigo a una audiencia. En efecto, la previa escrituración de su testimonio no sólo no es contraproducente para estos fines, sino que puede ser una herramienta útil para la parte contra la cual se presenta el testigo para hacer notar contradicciones u obtener nuevas contradicciones en la audiencia oral destinada a contrainterrogar al testigo. Por otra parte, también puede sostenerse que para la parte contra la que se hace valer un testimonio de un tercero imparcial resulta de utilidad conocer la importancia y contenido de dicha declaración, permitiendo en muchos casos descartar testimonios irrelevantes y centrarse en aquellos que sí pueden un efecto importante en la convicción del árbitro y que versan sobre hechos relevantes, produciendo una optimización de los esfuerzos de la parte que pretende impugnar o restar validez a la prueba.

En cuanto a las facilidades para mentir, si bien coincidimos con la crítica, en orden a que mentir resulta más fácil cuando la coartada se prepara con tiempo, lo que permite la escritura, pero que es atacado por la interrogación espontánea, en este punto corresponde hacer una ponderación sobre lo que resulte más importante para ambas partes al momento de fijar las normas de procedimiento. En otras palabras, no se vislumbra que esté en juego una garantía fundamental de todo proceso, sino simplemente una cuestión opinable, sobre lo que deberán razonar y acordar ambas partes. Por otra parte, no es un misterio para nadie dedicado a la litigación que los testigos generalmente estudian sobre los hechos sobre los cuales se les interrogará, disponiendo también del tiempo suficiente para la preparación de la declaración que se intenta evitar. Además, como se dijo, con el tiempo que media entre la agregación de la declaración escrita al expediente y la celebración de la audiencia testimonial, dispone la parte contraria de una oportunidad valiosísima para estudiar las contradicciones del testigo con la verdad, permitiéndole preparar un contrainterrogatorio mucho más fructífero que aquel que se da espontáneamente, sin que el interesado tenga mayor

${ }^{65}$ Crítica expuesta en Bordalí, Cortez y Palomo, cit. (n. 17), pp. 81 y ss. 
información sobre la importancia y contenido de la declaración presentada por su oponente, más allá de la remisión genérica a la resolución que fijó los hechos a probar.

En cuanto a la crítica sobre posibles contactos entre la parte o su abogado y el testigo que pondrían en entredicho su credibilidad ("preparación del testigo"), puede advertirse, sin mayor agudeza, que esta crítica no dice relación con la forma escrita u oral de rendir la testimonial, pues es aplicable a ambas. Con la forma escrita se transparenta esta posible circunstancia, pues se hace evidente que el abogado de la parte que presenta el testigo ha intervenido al menos en los aspectos formales para hacer presentable la declaración escrita, lo que facilita o entrega un argumento adicional para criticar y restar valor o credibilidad a partes del testimonio que sean evidentemente alineadas con el memorial de demanda o contestación, por ejemplo, o en que se incluyan frases de similar tenor.

Sobre la crítica basada en la ausencia de la posibilidad de percibir por los sentidos las reacciones del testigo, las cuales incidirían en su credibilidad, Bordalí, Cortez y PALOMo han expresado con gran precisión lo siguiente: "esta concepción de la oralidad es bastante criticable, en la medida que asume que en la producción de las pruebas se permite alcanzar 'algo más' que el acto meramente informativo, un 'valor agregado' distinto a la declaración de la parte o del testigo que puede ser valorado por el juez como elemento de juicio. Por el contrario, la oralidad no debería significar que el juez esté autorizado para valorar el carácter informativo de una declaración de hechos más allá del grado de confirmación epistémica que presta a una hipótesis fáctica. Hay que señalar, por lo demás, que los jueces en general no están preparados para la denominada 'psicología del testimonio'; a lo más pueden utilizar alguna experiencia que hayan tenido desde su posición de jueces, cuestión que no los habilita para realizar excursiones inescrutables en la mente de los testigos que están basadas en valoraciones apriorísticas, en prejuicios y predisposiciones. Un juez no está en condiciones de dar un valor epistémico a los signos o circunstancias externas que acompañan a la declaración" ${ }^{66}$ En resumidas cuentas, si coincidimos en que el juez no tiene -ni se espera que tenga- conocimientos de psicología que le permitan obtener conclusiones fundadas sobre los signos que ve en un testigo y en que por lo tanto, mal le puede servir su experiencia sensible para fundar la sentencia, podemos concluir que la crítica a la forma escrita de rendir la testimonial debe ser descartada. 
5.3. La respuesta que debe darse a la interrogante en base al principio de Autonomía de la Voluntad y sus límites.

Tomando en consideración lo ya expresado en relación con el principio de autonomía de la voluntad y su límite, es necesario tomar como punto de partida que en esta materia las partes tendrán plena libertad para acordar el procedimiento que estimen conveniente, siempre y cuando no afecten la garantía del debido proceso. Lo anterior, avalado por la abundante y constante tradición de los centros de arbitraje y de las leyes y reglamentos especiales sobre el particular, a los cuales nos hemos referido precedentemente.

Atendido que los procedimientos son algo mutable en el tiempo según las circunstancias, muchas veces determinados por consideraciones prácticas y de recursos disponibles, debe descartarse, en primer lugar, argumentos relativos a la conveniencia o inconveniencia de la forma oral por sobre la escrita, pues dicho análisis corresponde a las partes del compromiso al momento de fijar las bases de procedimiento, a quienes en esta materia se les ha reconocido libertad y capacidad para velar por sus propios intereses y asumir las consecuencias de sus actos. Descartado, entonces, este tipo de consideraciones prácticas -que deben confiarse a los propios interesados- la cuestión sólo debe interesar al Derecho en la medida que las partes acuerden reglas que vulneren la garantía del debido proceso, único criterio que podría servir a un juez para desconocer los actos libres y voluntarios desplegados por las partes al momento de fijar las reglas de procedimiento que han pactado.

Para estos efectos, y tal como se indicó en la sección III, corresponde en este punto referirnos a los principios o derechos que conforman el contenido de la garantía al debido proceso en relación con la posibilidad de rendir la testimonial mediante declaraciones escritas. Dichos principios, dejando a un lado el llamado derecho al recurso, por las razones expuestas en la sección antes referida, son el principio de igualdad de partes, el principio de imparcialidad y el derecho a la prueba.

Respecto de la igualdad de partes o de armas, estimamos que por el sólo hecho de permitir las declaraciones de testigos por escrito no se está confiriendo a una de las partes una ventaja indebida frente a la otra, al menos no una ventaja que la otra parte pueda usar también en su beneficio. Por ello, pareciera que no estamos frente a un problema de igualdad de armas, pues éstas son equivalentes.

En cuanto al principio de imparcialidad, estimamos que con la forma 
escrita no solamente se mantiene intacto, sino que se logra de mejor manera. En efecto, por las razones expresadas en la sección precedente, muchas veces prevalece la idea -a nuestro juicio equivocada- de que la percepción sensible del juez de ciertos comportamientos o actitudes del testigo le permiten fundar una conclusión en orden a dar o no valor a dicha prueba. Pues bien, admitiendo las declaraciones escritas otorgadas por testigos, muchos de los cuales no declararán además en audiencia, las partes y el juez están reconociendo implícitamente que el valor de la oralidad no viene dado por el análisis psicológico que hemos reprobado, sino que viene dado por haber contemplado una oportunidad-facultad para la contraparte y para el juez para contrainterrogar al testigo y obtener respuestas distintas o complementarias a las consignadas en su declaración escrita, primando siempre el valor de la declaración misma y no de los signos externos que la acompañen, que muchas veces pueden hacer que el juez pierda precisamente su carácter de tercero imparcial al momento de analizar la prueba concreta de que se trata.

En cuanto al derecho a la prueba, no vemos de qué manera la forma escrita u oral de rendir la testimonial, afecte el contenido de este principio, el cual dice relación -según se dijo- con que exista un período de tiempo adecuado durante el cual se reciban las diligencias probatorias, que cada parte tenga el derecho de proponer los medios de prueba que estime convenientes para acreditar sus pretensiones y, finalmente, que el medio de prueba sea admitido y correctamente valorado. ${ }^{67}$ Respecto de la valoración del medio de prueba, nos remitimos a lo ya expresado sobre que los signos externos del testigo perceptibles por los sentidos no forman parte del contenido que debe y puede valorar el juez en la sentencia.

Ahora bien, considerando como contenido de este derecho aquel que asiste a las partes en orden a controlar la producción de la prueba de su contraparte, estimamos que al contemplar la forma escrita una oportunidad para controvertir al oponente (y en la medida que se contemple dicha oportunidad), la práctica en estudio resulta plenamente compatible con dicho principio. La oportunidad de solicitar la parte contra la que se invoca el testimonio -o bien la facultad del juez para ordenar de oficio- la comparecencia personal del testigo, por motivos fundados, permite a dicha parte y al juez interrogar al testigo, despejar las dudas que su testimonio escrito pudiera arrojar o poner de manifiesto contradicciones entre la declaración escrita y la oral que preste en la audiencia correspondiente. En ese sentido, la forma

${ }^{67}$ Cfr. Ídem. 
escrita previa al interrogatorio resulta ser incluso una ventaja para controlar la producción de la prueba. Por otra parte, permitiéndose a la parte interesada no ejercer esta facultad o bien al juez rechazar la petición infundada, se está regulando un uso racional y económico de este medio de prueba que, de lo contrario, implicaría un despliegue de recursos y tiempo considerable en casos en que podría no justificarse por tratarse, por ejemplo, de un testigo que declara sobre un aspecto muy accesorio o bien irrelevante.

Como puede advertirse, resulta relevante reservar siempre la facultad del juez y de las partes para solicitar la comparecencia personal del testigo, sea porque es un testigo hostil que no quiere concurrir a declarar voluntariamente, ${ }^{68}$ sea porque es un testigo cuya idoneidad puede ponerse en duda por medio de un contrainterrogatorio, o bien que sea un testigo respecto del cual se sospecha que conoce los hechos en mayor profundidad que los declarados por escrito o conoce otros hechos que son relevantes para la resolución del asunto controvertido.

En este punto, resulta ineludible detenernos en el fundamento para pedir -y para negar- el contrainterrogatorio del testigo que ha declarado por escrito. Desde ya, hacemos presente que el derecho a pedir la audiencia de contrainterrogatorio consagrado en términos absolutos, no nos parece conveniente, pues impide conseguir el fin de economía procesal que se pretende, consistente en el ahorro de tiempo y recursos que implica no realizar audiencias innecesarias para interrogar testigos. Por ello, resulta conveniente exigir en las bases de procedimiento que sea necesario expresar el fundamento de la solicitud. Por otra parte, un criterio estricto, que exigiera fundamentos demasiado calificados para solicitar que se cite a los testigos de la contraparte que han declarado por escrito, podría atentar contra el derecho de una parte para controlar la producción de la prueba de su oponente. Entre estos dos vértices se moverá la decisión del juez, el cual debiera contar con criterios auxiliares que no estamos en condiciones de proporcionar, pero sobre los cuales al menos resulta útil dejar planteada la cuestión. De todas formas, en caso de duda, estimamos que la prudencia de todo juez se inclinará (y debiera inclinarse) por conceder el contrainterrogatorio que se le solicita, en tanto la jerarquía o ponderación de los bienes involucrados así lo aconseja.

${ }^{68}$ Hipótesis poco probable, pero posible. Para estos efectos, deberá citarse y compelerse por la justicia ordinaria, conforme a lo dispuesto en el artículo 633 del Código de Procedimiento Civil. 


\section{CONCLUSIONES}

De lo expresado en las páginas precedentes, resulta que la forma escrita para rendir la prueba testimonial es, por regla general, vedada en los procedimientos civiles ordinarios. Así es en nuestro derecho y en la generalidad de los sistemas analizados. Ello, con la salvedad de Francia y Alemania, países en los cuales, no obstante, el juez siempre puede requerir el examen en audiencia del autor de la declaración escrita.

En cuanto a las normas de procedimiento en el marco del arbitraje, la práctica en comento no sólo resulta aceptable, sino extremadamente corriente. Así, todos los reglamentos de los centros de arbitraje institucional analizados disponen explícitamente, al menos, la posibilidad de pactar las partes o disponer el juez que las testimoniales se rindan mediante declaraciones escritas, con el significativo ahorro que ello implica, especialmente cuando el testigo reside fuera del territorio del tribunal ordinario o de la sede del tribunal arbitral.

Las leyes de arbitraje internacional, por su parte, no disponen regla expresa sobre esta materia, salvo China e Italia -admitiendo la posibilidad en estudio-. No obstante ello, la práctica es muy utilizada en los arbitrajes internacionales que tienen su sede en todos los países analizados.

Es importante destacar, como lo hace el Código de Procedimiento Civil francés en los fragmentos transcritos más arriba, que resulta relevante para estos efectos que en el certificado se declaren cuestiones relativas a la imparcialidad del testigo, como asimismo que conste la autenticidad de la firma del declarante. Ello, además, reservando siempre la facultad del juez para interrogar en audiencia a algún testigo, sea para despejar las dudas sobre su imparcialidad, sea para obtener mayor información conocida por el testigo, o bien para permitir a la parte que lo presenta formular repreguntas o a su contraparte formular contrainterrogaciones, en los casos en que se justifique el empleo de los recursos necesarios para proceder de esta forma.

Bajo estas condiciones (es decir, resguardando el derecho a exigir fundadamente la comparecencia personal del testigo que ha declarado por escrito), pueden también descartarse -como se ha hecho- los reproches dogmáticos que pudieran formularse a esta práctica que resultan tan utilizada y eficiente en la tramitación de los procesos arbitrales. Ello, por cuanto no afectan a los derechos que conforman la garantía a un debido proceso. Dicha garantía, según se ha mencionado, es la herramienta fundamental para analizar las críticas a las reglas de procedimiento acordadas por las partes 
en el arbitraje, entre las que se encuentran la forma escrita $u$ oral de rendir la testimonial, algunas de las cuales se han planteado más arriba, a fin de acoger o desechar las referidas críticas.

\section{BIBLIOGRAFÍA CITADA}

a) Doctrina

Aylwin Azócar, Patricio, El Juicio Arbitral, Legal Publishing, Santiago, 2014, 6 a Ed. actualizada.

Bentham, Jeremy, Tratado de las pruebas judiciales, Editorial Jurídica Universitaria, México, 2001.

Blackaby, Nigel; Partasides, Constantine; Redfern, Alan; Hunter, Martin, Redfern and Hunter on international arbitration, Oxford University Press, Nueva York, 2009.

Bordalí Salamanca, Andrés; Cortez Matcovich, Gonzalo; Palomo Vélez, Diego, Proceso Civil. El juicio ordinario de mayor cuantía, procedimiento sumario y tutela cautelar, Legal Publishing, Santiago, 2014, $2^{\mathrm{a}}$ Ed.

Born, Gary, International Commercial Arbitration, Transnational Publishers, Nueva York, 2001, $2^{\text {a }}$ Ed.

Cortez Matcovich, Gonzalo; Palomo Vélez, Diego, Proceso Civil. Normas comunes a todo procedimiento e incidentes, Legal Publishing, Santiago, 2018.

Couture, Eduardo, Fundamentos del Derecho Procesal Civil, Editorial B. de F., Montevideo, 2002, $4^{\mathrm{a}}$ Ed.

Fernández Rozas, José Carlos, Tratado del Arbitraje Comercial en América Latina, Iustel, Portal Derecho, Madrid, 2008.

Kurkela, Matti; Turunen, Santtu, Due Process in International Commercial Arbitration, Oxford University Press, Nueva York, 2010, $2^{\text {a }}$ Ed.

KaufManN-Kohler, Gabrielle, "Globalization of Arbitral Procedure", Vanderbilt Journal of Transnational Law, 2003, Vol. 36, (Oct.), pp. 1313-1333.

Lessona, Carlo, Teoría de las pruebas en derecho civil, Editorial Jurídica Universitaria, México, 2001, Vol. II.

Merino Merchán, José F.; Chillón Medina, José Ma , Tratado de Derecho Arbitral, Ed. Aranzadi, Pamplona, 2014, $4^{\text {a }}$ Ed.

Ossa Guzmán, Felipe; Zamora Wilson, Rosana, El Arbitraje Internacional en la Jurisprudencia, Editorial Legal Publishing, Santiago, 2014.

Paúl DíAz, Álvaro, "Prueba Testifical y Pericial en la Práctica de la Corte Interamericana de Derechos Humanos", Ius et Praxis, 2019, Año 25, № 1, pp. 1948. 
Philippi IzQuierdo, Julio, "Notas sobre el juicio seguido ante arbitradores", Revista de Estudios Jurídicos (PUC), 2013, Vol. 2, Nº 1-2, archivo de la Cámara de Arbitraje y Mediación de Santiago, disponible en línea: http://www.camsantiago. cl/articulos_online/20_Notas_sobre_juicio_seguido.pdf. (fecha de visita: 19 de agosto de 2018).

Robles-Garzón (dir.), Conceptos Básicos de Derecho Procesal Civil, Tecnos, Madrid, 2012, $3^{\mathrm{a}}$ Ed.

Romero Seguel, Alejandro. Curso de Derecho Procesal Civil. Tomo III. Los Presupuestos Procesales Relativos al Procedimiento, Legal Publishing, Santiago, 2015.

Romero Seguel, Alejandro; Díaz Villalobos, José Ignacio, El arbitraje interno y comercial internacional (parte general), Eds. Universidad Católica de Chile, Santiago, 2016, $2^{\mathrm{a}}$ Ed. actualizada.

VÁsquez Palma, María Fernanda, Tratado de arbitraje en Chile. Arbitraje interno e internacional, Legal Publishing, Santiago, 2018.

WeIgand, Frank-Bernd, Practitioner's Handbook on International Commercial Arbitration, Oxford University Press, Nueva York, 2009.

Yrarrázaval Covarrubias, Arturo, Diccionario Jurídico-Económico, Ediciones Universidad Católica de Chile, Santiago, 2011.

\section{b) Normativa citada}

Código Civil chileno (1856), D.F.L. $\mathrm{n}^{\circ} 1,2000$.

Código Orgánico de Tribunales chileno, Ley $N^{\circ} 7.421,1943$.

Código de Procedimiento Civil chileno, Ley $\mathrm{N}^{\circ} 1552,1902$.

Ley $n^{\circ} 19.471$ de 2004, sobre Arbitraje Comercial Internacional.

Bases para Preparación del Código Procesal Civil Modelo para Iberoamérica (1988), documento disponible en línea: http://iibdp.org/images/ C\%C3\%B3digos\%20Modelo/IIDP_Codigo_Procesal_Civil_Modelo Iberoamerica.pdf (visitado el 19 de agosto de 2018).

Código Procesal Civil Modelo para Iberoamérica (1988), documento disponible en línea: http://ibdp.org/images/C\%C3\%B3digos\%20Modelo/IIDP Codigo_Procesal_Civil_Modelo_Iberoamerica.pdf(visitado el 19 de agosto de 2018).

Código Procesal Civil alemán - ZPO (1867) reformada el 2005, Gaceta de Leyes Federales I, p. 3202, versión traducida al inglés, disponible en línea: http:// www.gesetze-im-internet.de/englisch_zpo/index.html (visitada el 19 de agosto de 2018).

Código Procesal Civil francés (1976), archivo disponible en línea: https:// www.legifrance.gouv.fr/content/location/1758 (visitada el 19 de agosto de 2018).

Código Procesal de la Nación Argentina (1981), Ley $\mathrm{N}^{\circ} 17.454$ de 1981, disponible en línea: http:/www.legislaw.com.ar/legis/cpcc\%20completo/ 
cpcclibrosegundo.htm (visitada el 19 de agosto de 2018).

Código General del Proceso Uruguayo (1988), archivo disponible en línea: https://www.iberred.org/sites/default/files/cdigo-procesal-civiluruguay.pdf (visitada el 19 de agosto de 2018).

Ley $\mathrm{N}^{\circ}$ 1-2000, Ley de Enjuiciamiento Civil española (2000), archivo disponible en línea: https:/www.boe.es/buscar/doc.php?id=BOE-A-2000-323 (visitada el 19 de agosto de 2018).

Ley $\mathrm{N}^{\circ} 113$ de 1895, Austrian Arbitration Act, Sección 577-618 del Código de Procedimiento Civil austríaco, documento en pdf., disponible en línea: http:// www.viac.eu/images/ZPO_Schiedsrecht_2014_en_im_VIAC_Layout.pdf (visitado el 19 de agosto de 2018).

Arbitration Law of the People's Republic of China (1994), archivo disponible en línea: http://www.npc.gov.cn/englishnpc/Law/2007-12/12/content_1383756.htm (visitado el 19 de agosto de 2018).

U.K. Arbitration Act, de 1996, documento disponible en línea: http://www. legislation.gov.uk/ukpga/1996/23/section/34 (visitada el 19 de agosto de 2018).

Decreto Legislativo $\mathrm{N}^{\circ} 40$, de 2006, modifica el Código de Procedimiento Civil italiano, disponible en línea: http://www.camera.it/parlam/leggi/deleghe/06040dl. htm (visitada el 19 de agosto de 2018).

\section{c) Reglamentos de centros de arbitraje citados}

Reglamento de Arbitraje de la CNUDMI (1966), revisión de 2010, ONU, Nueva York, 2011, texto en español, archivo .pdf, disponible en línea: https://www. uncitral.org/pdf/spanish/texts/arbitration/arb-rules-revised/arb-rules-revised-s.pdf, visitado el 19 de agosto de 2018.

Administered Arbitration Rules (2013), Reglamento del Centro de Arbitraje Internacional de Hong Kong, documento en .pdf, disponible en línea: http:// www.hkiac.org/sites/default/files/ck_filebrowser/PDF/arbitration/2013_hkiac_ rules\%28en_es\%29.pdf (visitada el 19 de agosto de 2018).

Corte Española de Arbitraje (2011), archivo disponible en línea: http:// corteespanolaarbitraje.es/wp-content/uploads/2014/05/reglamento-corte-espanolade-arbitraje-en-vigor-desde-el-15-03-2011.pdf (visitado el 19 de agosto de 2018).

Reglamento sobre Práctica de Prueba en el Arbitraje Internacional de la International Bar Association (2010), IBA, Londres, 2010, texto no oficial en español, disponible en línea: https://www.ibanet.org/Document/Default. aspx?DocumentUid=3599492E-8BC6-4E3D-A205-B86B69A42593 (visitada el 19 de agosto de 2018).

London Court of International Arbitration Rules (2014), documento disponible en línea: http://www.lcia.org/Dispute_Resolution_Services/lcia-arbitrationrules-2014.aspx\#Article\%2020 (visitada el 19 de agosto de 2018). 